\title{
Proline isomerisation as a novel regulatory mechanism for p38MAPK activation and functions
}

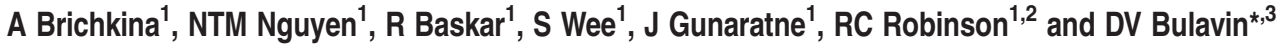

The stress-induced p38 mitogen-activated protein kinase (MAPK) pathway plays an essential role in multiple physiological processes, including cancer. In turn, p38MAPK phosphorylation at Thr180 and Tyr182 is a key regulatory mechanism for its activation and functions. Here we show that this mechanism is actively regulated through isomerisation of Pro224. Different cyclophilins can isomerise this proline residue and modulate the ability of upstream kinases to phosphorylate Thr180 and Tyr182. In vivo mutation of Pro224 to lle in endogenous p38MAPK significantly reduced its phosphorylation and activity. This resulted in attenuation of p38MAPK signalling, which in turn caused an enhanced apoptosis and sensitivity to a DNA-damaging drug, cisplatin. We further found a reduction in size and number of lesions in homozygous mice carrying the p38MAPK P224I substitution in a K-ras model of lung tumorigenesis. We propose that cyclophilin-dependent isomerisation of p38MAPK is an important novel mechanism in regulating p38MAPK phosphorylation and functions. Thus, inhibition of this process, including with drugs that are in clinical trials, may improve the efficacy of current anti-cancer therapeutic regimes.

Cell Death and Differentiation (2016) 23, 1592-1601; doi:10.1038/cdd.2016.45; published online 27 May 2016

Mitogen-activated protein kinases (MAPKs) have long been known to link extracellular stimuli to cellular responses such as survival, proliferation and apoptosis. p38MAPK (with reference to MAPK14 or p38a) was originally implicated in the inflammatory response, ${ }^{1,2}$ but subsequently shown to be activated in response to multiple stressors, including UV radiation, hyperosmolarity, oxidative stress and DNA damage, and in cancer. ${ }^{3-6}$ Initial experiments using mouse models of cancer showed that p38MAPK suppresses lung and liver tumour formation in vivo.,8 However, enhanced p38 phosphorylation also correlates with poor prognosis in some patients with breast cancer and hepatocellular carcinoma., 9 Similarly, overexpression or activation of p38MAPK has been reported in lymphomas, thyroid neoplasms and human lung tumours. ${ }^{11-13}$ In addition, inhibition of p38MAPK activity enhances apoptosis and cell sensitivity during administration of chemotherapy drugs. ${ }^{14-17}$ The key regulatory sequence within p38MAPK is Thr180-Gly181-Tyr182, in which Thr and Tyr residues are phosphorylated to increase p38MAPK activity by allowing easier access to its active site. ${ }^{18}$ Whether there are additional mechanisms to control p38MAPK activity and functions however remains largely unknown.

Key proline residues in native proteins can play important roles in the regulation of protein activity and function. Peptidylprolyl isomerisation can affect protein conformation, modulating protein activity, phosphorylation status, protein-protein interactions, subcellular localisation and stability. Proline isomerisation acts as a spatial and temporal regulatory mechanism for a variety of proteins, including cyclin-dependent kinases, the tumour suppressor p53, the transcription factors c-Jun and c-Fos, histone $\mathrm{H} 3$ and JNK kinase. ${ }^{19-22}$ Cyclophilins are one of the subfamilies of prolyl cis-trans isomerases, have been structurally conserved throughout evolution and seven major isoforms are ubiquitously expressed in multiple tissues.

Here we report a new mechanism to control activation of p38MAPK through its isomerisation mediated by cyclophilins and show its significance in the regulation of p38MAPK functions in cancer. We have identified Pro224 in the protein sequence of p38MAPK as a key proline residue targeted by multiple cyclophilins. We observed that direct association of cyclophilins increases phosphorylation of p38MAPK by MKK6 kinase, which in turn leads to activation of a signalling pathway downstream of p38. Attenuation of cyclophilins or mutation of Pro224 in endogenous p38MAPK blocks isomerisation, leading to a similar physiological outcomes - the increased sensitivity of tumour cells to the chemotherapy drug cisplatin in vitro and in a mouse lung cancer model in vivo. Moreover, mice lacking the isomerisation of p38MAPK do not efficiently develop lung tumours, suggesting that isomerisation of p38MAPK is required for tumorigenesis.

\footnotetext{
${ }^{1}$ Institute of Molecular and Cell Biology, A*STAR (Agency for Science, Technology and Research), Biopolis, Singapore 138673, Singapore; ${ }^{2}$ Department of Biochemistry, Yong Loo Lin School of Medicine, National University of Singapore, Singapore 117597, Singapore and ${ }^{3}$ Institute for Research on Cancer and Aging of Nice (IRCAN), INSERM, U1081-UMR CNRS 7284, University of Nice - Sophia Antipolis, Centre Antoine Lacassagne, Nice, France

${ }^{*}$ Corresponding author: D Bulavin, IRCAN, 28 Av Valombrose, 06107 Nice, France. Tel: +33 4 93377782, Fax: +33 493 377676,

E-mail: Dmitry.Bulavin@unice.fr

Abbreviations: MAPK, mitogen-activated protein kinases; Thr, threonine; Tyr, tyrosine; Pro, proline; Gly, glycine; UV, ultraviolet; MK2, mitogene-activated protein kinaseactivated protein kinase 2; MKK, matogen-activated protein kinase kinase 3; JNK, c-Jun N-terminal kinase; Pin1, peptidyl-prolyl cis-trans isomerase NIMA-interacting 1; Cyp, cyclophilin; SILAC, stable isotope labelled amino acids in cell culture; GFP, green fluorescent protein; RNA, ribonucleic acid; DNA, deoxyribonucleic acid; Arg, arginine; TNF, tumour necrosis factor; BrdU, bromodeoxyuridine; MEF, mouse embryo fibroblasts; Cxcl5, C-X-C motif chemokine 5; PPlase, peptidyl-prolyl-cis-transisomerase; NF-B, nuclear factor kappa-light-chain-enhancer of activated B cells; shRNA, small hairpin ribonucleic acid Received 13.11.15; revised 05.4.16; accepted 15.4.16; Edited by P Salomoni; published online 27.5.2016
} 


\section{Results}

Cyclophilins interact with p38MAPK and increase the phosphorylation of its regulatory sequence. p38MAPK is activated by dual phosphorylation of Thr180 and Tyr182 in response to a variety of factors. It is not known, however, whether there are any binding partners or scaffolding proteins that regulate this activating event. We hypothesised that p38MAPK phosphorylation, and thus its activity and function, could be regulated by direct association with certain proteins. This regulation in turn could happen if the interacting partner either facilitates or disrupts the ability of upstream kinases such as MKK6 to phosphorylate p38MAPK. To identify potential p38MAPK binding partners, we used a stable isotope labelled amino acids in cell culture (SILAC)-based quantitative proteomic strategy and HeLa cells with stably expressed green fluorescent protein (GFP)-tagged p38MAPK for immunoglobulin-free purification. HeLa cells expressing p38MAPK-GFP were exposed to UV irradiation $\left(20 \mathrm{~J} / \mathrm{m}^{2}\right)$ and precipitated p38MAPK was subjected to SILAC-based quantitative mass spectrometry. We found that multiple peptidyl-prolyl cis-trans isomerases (PPlase), including СурA, СурB, СypH, CypE, CypG, CWC27 and PPIL4, were associated with p38MAPK. To validate the SILAC experiments, we performed a co-immunoprecipitation assay of transiently transfected cells with flag-tagged CypA, СypB and CypH together with p38MAPK. Consistent with the SILAC results, we observed p38MAPK binding with different cyclophilins (Figure 1a). Furthermore, we observed a strong interaction between endogenous CypA and GFP-tagged p38 (Figure 1b) as well as endogenous p38MAPK and flagtagged CypA (Figure 1c) and CypB (Figure 1d).

Because phosphorylation of p38MAPK is regulated by upstream kinases, including MKK6, we asked whether the cyclophilins/p38MAPK interaction could affect this regulatory event such as phosphorylation at Tyr182 or both Thr180/ Tyr182. We co-transfected HeLa cells with p38MAPK, constitutively active MKK6 (MKK6-EE) and increasing concentrations of different cyclophilins identified in SILAC experiments. We found that all tested cyclophilins (A, B, H, CWC27) increased phosphorylation of p38MAPK at both Thr180 and Tyr182 (Figure 2a and Supplementary Figure S1a). To understand whether this effect could be direct, we carried out similar experiments with bacteria-purified p38MAPK, MKK6 and CypA in vitro. We found that inclusion of CypA or CypB resulted in increased phosphorylation of recombinant p38MAPK by MKK6 (Figure $2 b$ and Supplementary Figure S1b).

For further analysis we focused on CypA, one of the most highly abundant and ubiquitously expressed cyclophilins. The level of CypA and p38MAPK was depleted after infection with a lentivirus containing a short hairpin (sh)RNA (Supplementary Figures S2a and b), and cells were selected and tested under different stress conditions. We found that levels of phosphorylated p38MAPK, and its activity based on analysis of the downstream targets MK2 and HSP27, were significantly reduced in CypA-depleted cells when compared with control cells; this result was observed for both HeLa and HCT116 cells (Figure 2c).
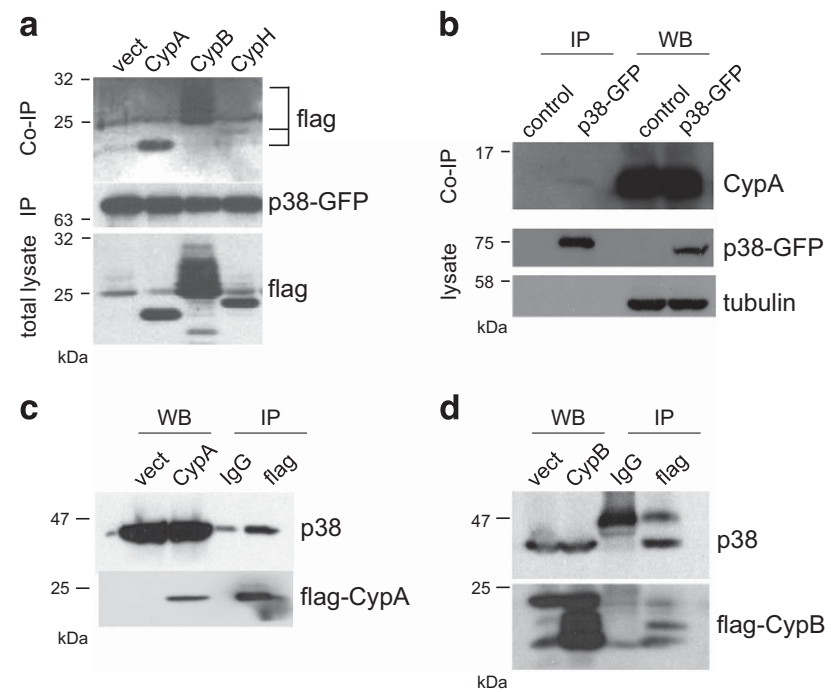

Figure 1 p38MAPK interacts with cyclophilins. (a) HeLa cells were transiently transfected with GFP-tagged p38MAPK together with either an empty vector or flagtagged cyclophilins. After GFP-trap pulldown, cyclophilins were detected by western blotting with an anti-flag antibody. Overexpressed p38MAPK was detected with antip38MAPK antibodies. (b) HeLa cells were transiently transfected either with empty vector or with plasmid coding GFP-tagged P38MAPK. Total cell lysates were incubated with GFP-trap beads and endogenous cyclophilin A bound to p38MAPK was detected with anti-cyclophilin antibodies. Efficiency of transfection and precipitation was analysed by staining with a p38MAPK antibody. (c) Hela cells were transfected with either flag-tagged CypA (c) or CypB (d) or with a backbone vector as a control. CypA and CypB were pooled down with anti-flag beads, control cell lysates were incubated with IgG followed by protein A-Sepharose pool down. Endogenous p38 bound to CypA and CypB was detected with anti-p38 antibodies. Efficiency of precipitation was analysed by staining with anti-flag antibodies

To understand whether chemical inhibition of cyclophilins could attenuate activation of p38MAPK, next we treated HeLa cells with the potent chemical cyclophilin inhibitor TMN355 and analysed p38MAPK activation in response to cisplatin. Phosphorylation of p38MAPK and its target MK2 was significantly reduced in the presence of the drug (Figure $2 d$ ). Together with the results of overexpression and knockdown experiments (Figure 2), these data strongly argue that cyclophilins play an important role in the regulation of p38MAPK phosphorylation and activity under different conditions.

Cyclophilins facilitate peptidyl prolyl cis-trans isomerisation of Pro224. CypA is a phosphorylation-independent peptidyl prolyl cis-trans isomerase, and as other isomerases, CypA isomerises the peptide bonds preceding a proline amino acid. As the presence of CypA is essential for p38MAPK phosphorylation and activity (Figure 2), we next speculated that the interaction of CypA with p38MAPK could change the conformational state of p38MAPK, thus modulating the ability of upstream kinases such as MKK6 to phosphorylate Thr180 and Tyr182. To predict potential prolines for which a conformational change could effect Thr180 and Tyr182 phosphorylation, we identified three proline residues based on their close proximity to phosphorylation sites in a 3D protein structure, PDB coordinates 3DT1. ${ }^{23}$ Firstly, Pro29 is involved in configuring the 


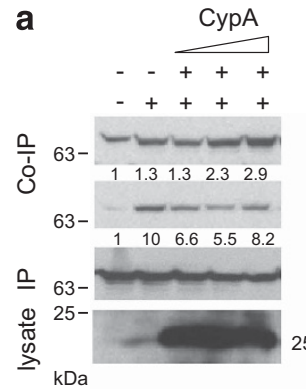

C

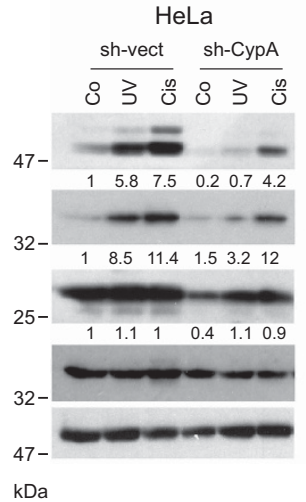

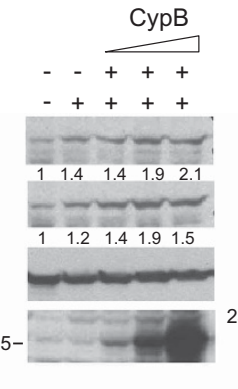
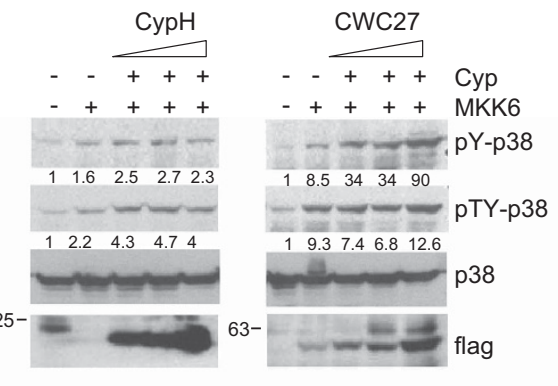

b

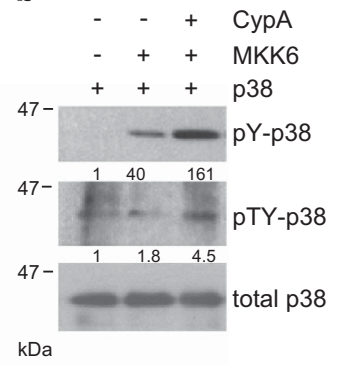

d
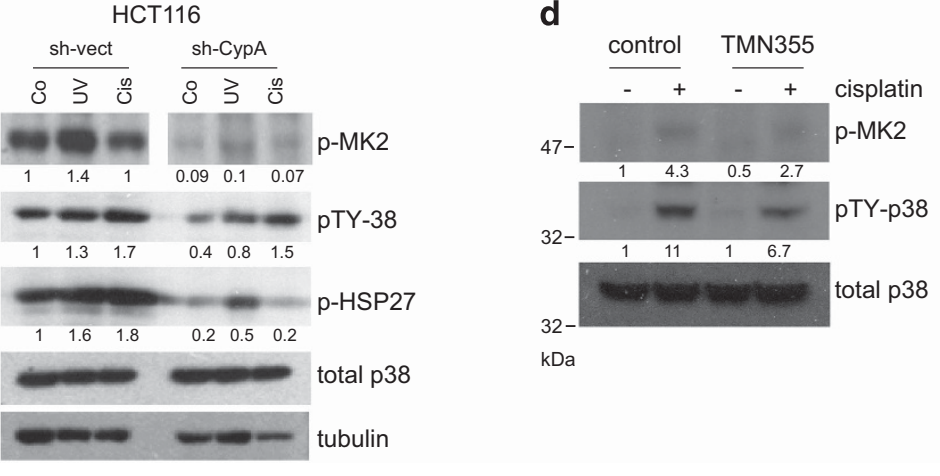

$\mathrm{kDa}$

Figure 2 Cyclophilins regulate p38MAPK phosphorylation. (a) HeLa cells were co-transfected with GFP-tagged p38MAPK, active MKK6-EE and increasing concentrations of different cyclophilins. p38MAPK was immunoprecipitated with GFP-trap beads and phospho-Tyr182 or phospho-Thr180/Tyr182 p38MAPK was detected in western blots with phospho-specific antibodies. Intensity of bands was quantified using a Gel-Pro program and presented as a ratio to the total p38 level, non-treated control cells were served as 1. This quantification strategy was used for all western blots presented. (b) Phosphorylation of bacteria-purified p38MAPK by active MKK6 was analysed in the presence of CypA. Phosphorylated forms of p38MAPK were detected in western blots with specific antibodies. (c) HeLa and HCT116 cells were infected with either a control lentivirus or a lentivirus containing an shRNA targeting CypA. Cells were collected 15 min after treatment with UV irradiation $\left(20 \mathrm{~J} / \mathrm{m}^{2}\right)$ or $4 \mathrm{~h}$ after treatment with $100 \mu \mathrm{M}$ cisplatin, and subjected to western blot analysis with phospho-specific antibodies. The efficiency of shRNA knockdown was measured by qPCR and presented in Supplementary Figures S1a and b. (d) HeLa cells were preincubated with the cyclophilin inhibitor TMN355 $(1 \mu \mathrm{M})$ for 10 min before adding $100 \mu \mathrm{M}$ cisplatin for $4 \mathrm{~h}$. Control cells were treated with dimethyl sulphoxide. Cells were harvested $4 \mathrm{~h}$ after cisplatin treatment in the absence or presence of TMN355 and subjected to western blot analysis with specific antibodies as indicated

ATP-binding site, although it is distant from the activation loop, residing on the opposite side of the ATP-binding cleft to Thr180 and Tyr182. Secondly, Pro153 is adjacent to Lys152, which packs against Thr185 and plays a structural role in position of the activation loop. However, while Pro153 is favourably placed to influence the positioning of Thr180 and Tyr182, it is buried in the crystal structure and most likely inaccessible to the cyclophilins. Finally, Pro224 is a solvent exposed residue that packs against Tyr187, which in turn contacts Tyr182 (Figure 3a). Furthermore, the carbonyl of the subsequent amino acid (225) forms a hydrogen bonding network which includes Tyr187 and Arg186, which in turn hydrogen bonds to the carbonyl of residue 181. Since, residue 181 lies between the Thr180 and Tyr182, isomerisation of Pro224 would have an effect on the ordering of the activation loop in which they are located. A switch between trans (Figure $3 \mathrm{a}$ ) and cis proline conformations will flip the carbonyl bond by $180^{\circ}$ and prevent Pro224 from simultaneously interacting with Trp187 while the carbonyl of residue 225 positions residue 181 through Arg186. This disruption of the stabilising network may alter the accessibility of Thr180 and Tyr182 to phosphorylation.

In accordance with established protease-coupled proline isomerisation assay, ${ }^{24}$ three peptides were designed containing a candidate proline followed by a phenylalanine $(F)$ and paranitroanaline (pNA) group: RTLFP-F-pNA (Pro224), RDLKP-F-pNA (Pro153) and QNLSP-F-pNA (Pro29). Chymotrypsin exclusively cleaves these peptides in the trans-proline conformation and does so with kinetics much faster than isomerisation of proline in water. Thus, the cis-trans conversion rate can be measured spectrophotometrically by the chymotrypsin-dependent release of pNA. Using this assay, the cyclophilins СypA, СурB, СypE and CypH were seen to have cis to trans isomerase activity on only the RTLFP-F-pNA (Pro224) peptide (Figure 3b), but not the two other peptides (Figure 3c). Importantly, we tested cyclophilin D, which was not found in our SILAC experiments and showed no isomerase activity towards the Pro224 peptide (Figure 3b).

Pro224 is required for full activation of p38MAPK. To understand the importance of p38MAPK isomerisation, Pro224 was substituted with isoleucine (P224I) to block any possible isomerisation by cyclophilins. Mutated p38MAPK was tested in in vitro and in vivo phosphorylation assays in the presence of active MKK6, as well as after different stresses. Wild type (wt) and P224I bacteria-expressed p38MAPK were incubated with active MKK6, and the phosphorylation of p38MAPK was analysed. As shown in Figure $4 a$ and Supplementary Figure S3a, mutation of Pro224 significantly reduced this phosphorylation. 
a
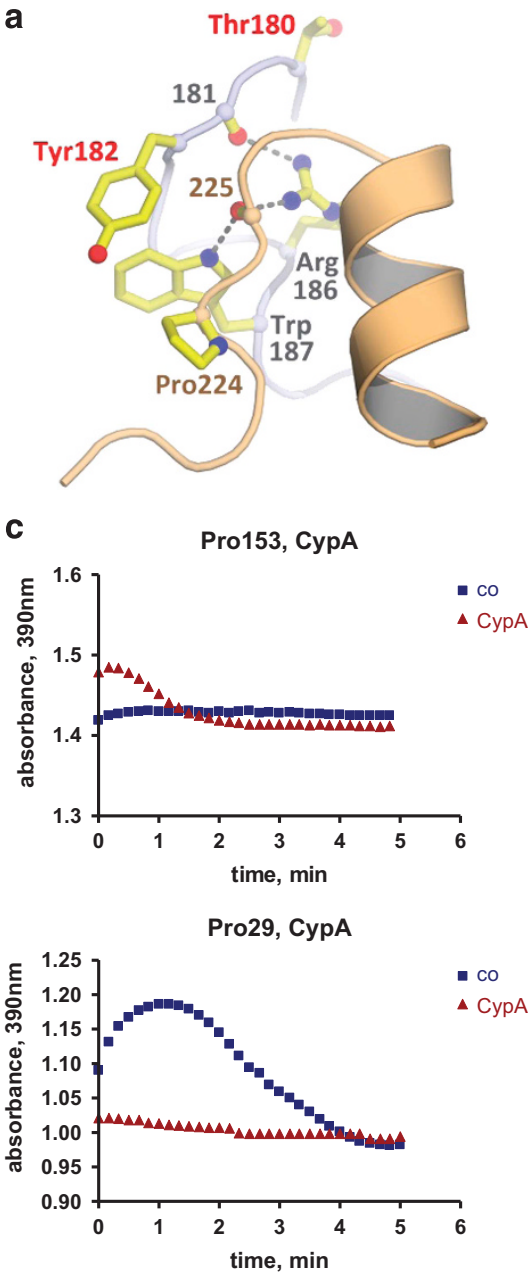

b

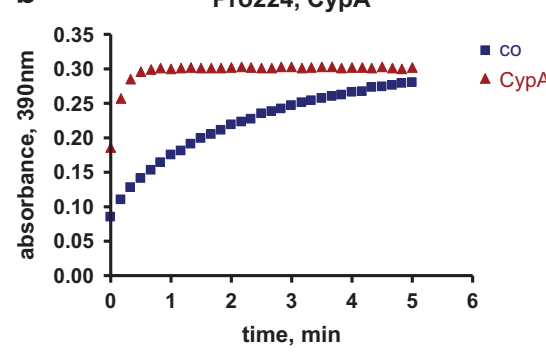

Pro224, CypD

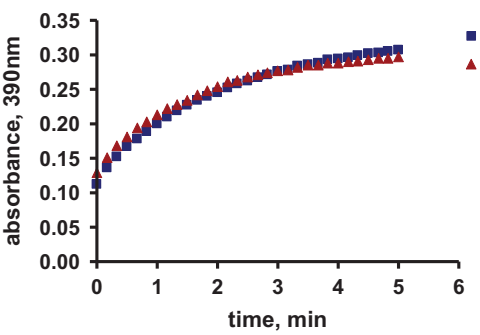

Pro224, CypF

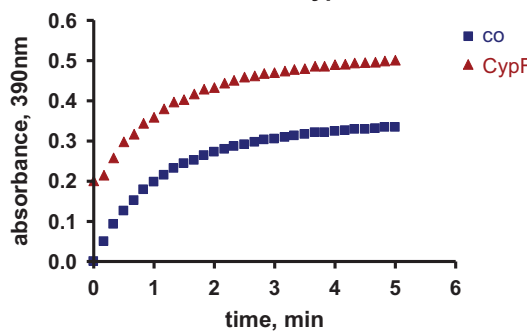

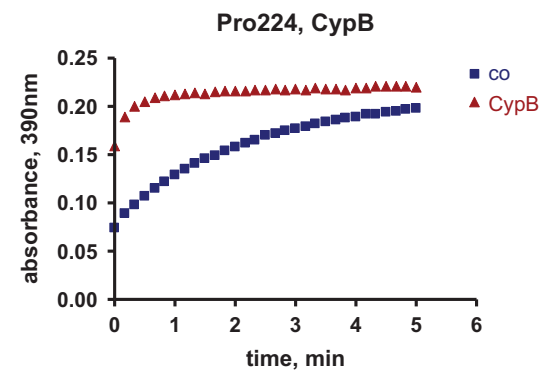

Pro224, CypE

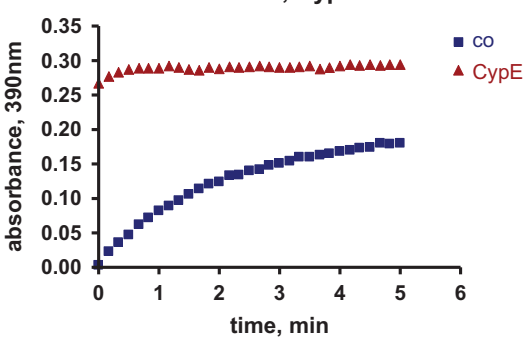

Pro224, СурH

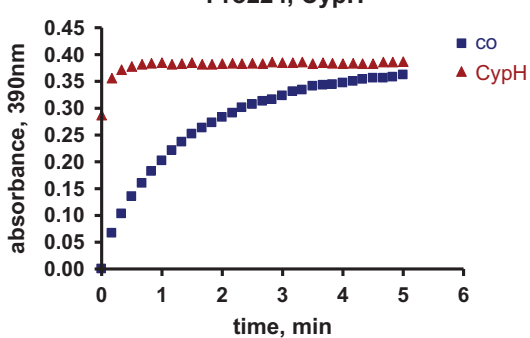

Figure 3 Cyclophilins facilitate peptidyl prolyl cis-trans isomerisation of Pro224. (a) The structure of p38MAPK showing the environment of Pro224. The stretch of amino acids that include the phosphorylated residues (Thr180 and Tyr182; labelled in red) has the main chain coloured grey, while the main chain proximal to Pro224 is shown in orange. Residues outside these regions are omitted for clarity. Peptidyl-prolyl cis-trans isomerisation assay of Pro224 peptide (b) or Pro153 and Pro29 peptides (c) incubated with or without cyclophilins. The substrate peptide RTLFP-F-pNA was dissolved in LiCl/TFE buffer and preincubated with cyclophilins at $0^{\circ} \mathrm{C}$ for 30 min. To initiate the reaction, chymotrypsin was added to digest the peptide in trans thus to release the fluorophore. The absorbance was immediately recorded at $390 \mathrm{~nm}$. The $x$-axis is minutes; the $y$-axis is absorbance

Similar data were obtained in vivo after transfecting HeLa cells with p38MAPK and increasing concentrations of active MKK6 (MKK6-EE), using both GFP- (Figure 4b) and histagged p38 (Supplementary Figure S3b). These results further support the critical role of Pro224 in phosphorylation of p38MAPK by MKK6. To understand further how Pro224 isomerisation could affect the p38MAPK response to different types of stress, we transfected HeLa cells with either wt or P224I p38MAPK and treated them with $20 \mathrm{~J} / \mathrm{m}^{2} \mathrm{UV}$ radiation, $10 \mathrm{ng} / \mathrm{ml}$ tumour necrosis factor $a(\mathrm{TNF} a)$ or $0.5 \mathrm{M}$ sorbitol. Stress-induced phosphorylation of p38MAPK was significantly reduced when Pro224 was substituted with isoleucine (Figure 4c and Supplementary Figure S3c).

To unequivocally demonstrate the significance of p38MAPK isomerisation at Pro224, we next generated p38MAPK knockin mice in which Pro224 was substituted with isoleucine. p38MAPK P224I heterozygous mice were intercrossed, and mouse embryo fibroblasts (MEFs) were established. Primary cultures of two different pairs of wt and P224I MEFs were used for further analysis of p38MAPK phosphorylation. We found that p38MAPK phosphorylation at both Thr180 and Tyr182 as well as phosphorylation of MK2, a downstream target of p38MAPK, was significantly reduced after UV irradiation in both cultures of MEFs carrying the P224I substitution (Figure $5 \mathrm{a}$ and Supplementary Figure S4a). Furthermore a significant reduction in these changes could not be due to attenuation of the activity of upstream kinases in P224I p38MAPK mutant cells because our analysis of MKK3 and MKK6 revealed no difference in their phosphorylation when compared with wt cells (not shown).

Next, we transformed wt and P224I MEFs with E1A and RasV12 oncogenes to determine whether isomerisation is involved in regulating p38MAPK function in response to different stresses as well as to cisplatin treatment. Transformed cells were treated with $100 \mu \mathrm{M}$ cisplatin for $4 \mathrm{~h}$ (Figure 5b and Supplementary Figure 4b), UV irradiation or $0.5 \mathrm{M}$ sorbitol for $15 \mathrm{~min}$ (Figure $5 \mathrm{~b}$ ). We found that in response to all the treatments, the phosphorylation of both p38MAPK 

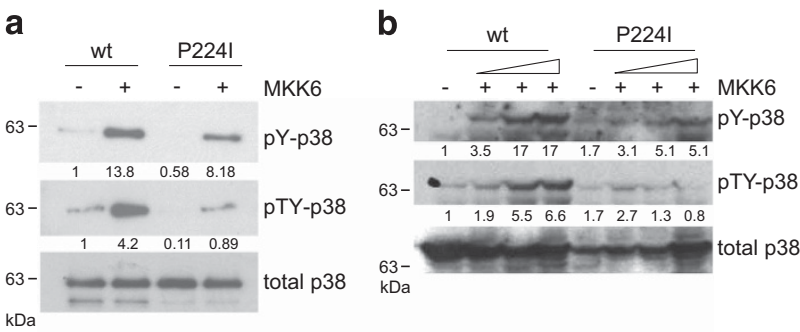

C

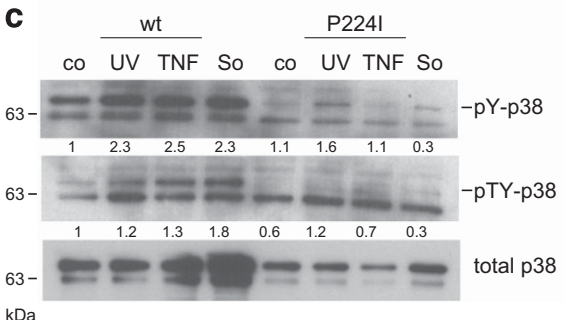

Figure 4 Mutation of Pro224 results in a significant reduction of p38MAPK phosphorylation. (a) In vitro kinase assays with recombinant wild-type P38MAPK or mutated p38MAPK, in which Pro224 was substituted with lle, were performed in the presence or absence of active MKK6. Phosphorylated forms of p38MAPK were detected by western blot analysis using specific antibodies. (b) HeLa cells were transiently co-transfected with GFP-tagged p38MAPK and increasing concentrations of active MKK6 (MKK6-EE). Subsequently, p38MAPK was pulled-down using GFPtrap beads and the phosphorylated forms of GFP-p38MAPK were detected with specific antibodies in western blot analysis. (c) HeLa cells were transiently transfected with GFP-tagged wild type or P224I p38MAPK. Twenty-four hours after transfection cells were either left untreated or treated for 15 min with $20 \mathrm{~J} / \mathrm{m}^{2} \mathrm{UV}$ irradiation, $10 \mathrm{ng} / \mathrm{ml}$ TNF $\alpha$ or $0.5 \mathrm{M}$ sorbitol. Cells were subjected to GFP-trap immunoprecipitation followed by western blot analysis with phospho-p38-specific antibodies

and MK2 was significantly reduced when Pro224 was mutated. Thus, we confirmed in vivo that intact Pro224 is important for efficient p38MAPK phosphorylation and activation.

Isomerisation of p38MAPK by cyclophilin A mediates sensitivity of tumour cells to cisplatin. Downregulation of p38MAPK sensitises tumour cells to the DNA damageinducing agent cisplatin. ${ }^{17}$ In turn, CypA is upregulated in a wide range of human cancers, and there is a strong correlation between overexpression of CypA, malignant transformation and cisplatin sensitivity. ${ }^{25,26}$ Despite these findings, the precise mechanism of how CypA mediates sensitivity to cisplatin is unclear. Similar to cyclophilin overexpression in cancer, an increase in p38MAPK phosphorylation has also been found in different tumours, which in turn correlates with poor prognosis and resistance to cisplatin treatment. ${ }^{9,10,25,27}$ Considering the strong correlation among p38MAPK, cyclophilins and sensitivity to cisplatin, we next speculated that p38-dependent sensitivity of tumour cells to cisplatin could be, at least in part, mediated through СypAdependent isomerisation of Pro224.

To verify this, we tested the viability of two tumour cell lines, HeLa and HCT116, after knocking down CypA in the presence of different doses of cisplatin. In addition, we established cell lines with reduced expression of p38MAPK with a stable shRNA knockdown approach to use as controls. Clonogenic
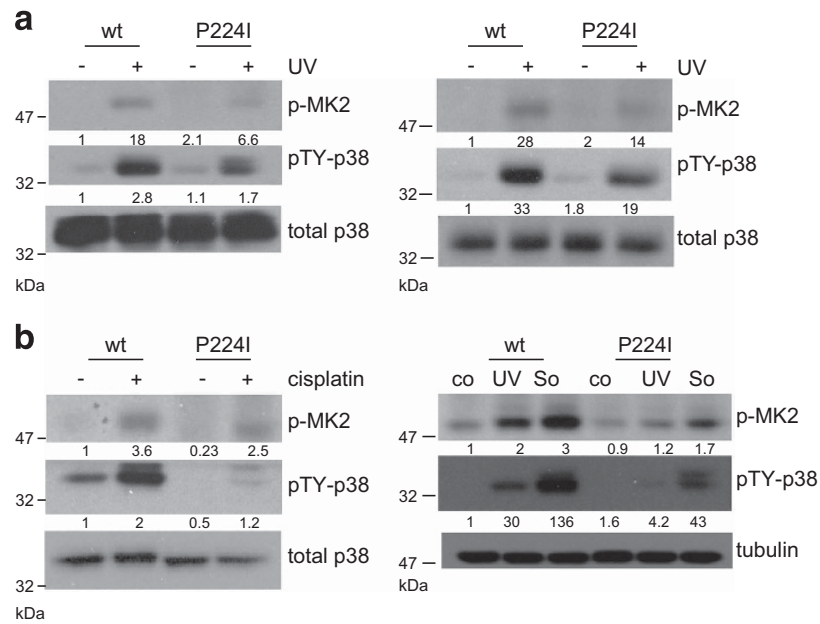

Figure 5 Intact Pro224 is required for efficient p38MAPK activation. (a) Mouse embryo fibroblasts (MEFs) were isolated from two pairs of either wild type or P224I knock-in embryos obtained from different litters at $12.5 \mathrm{dpc}$. Cells were treated with $20 \mathrm{~J} / \mathrm{m}^{2} \mathrm{UV}$ irradiation for $15 \mathrm{~min}$, harvested and subjected to western blot analysis with specific antibodies. Left and right panels - two different pairs of wild type and P224I MEFs. (b) MEFs from wild type and P224l knock-in embryos were transformed with $\mathrm{E} 1 \mathrm{~A}$ and RasV12 oncogenes. Established cell lines were treated with $100 \mu \mathrm{M}$ cisplatin for $4 \mathrm{~h}$ (left panel), with $20 \mathrm{~J} / \mathrm{m}^{2} \mathrm{UV}$ or $0.5 \mathrm{M}$ sorbitol for $15 \mathrm{~min}$ (right panel), harvested and total cell lysates were subjected to western blot analysis with phosphospecific antibodies as indicated

survival analysis confirmed that knockdown of CypA or p38MAPK had similar effects - an increase in cisplatin sensitivity of HeLa (Figure 6a and Supplementary Figure S5a) and HCT116 (Figure 6b) cells. Moreover, HeLa cells deficient for CypA and p38MAPK showed low viability when plated at clonal density (Figure 6a). Low colony numbers did not depend on changes in the proliferation rate of either CypA- or p38MAPK-depleted tumour cells because bromodeoxyuridine (BrdU) incorporation was similar to that of vector-transfected cells (Supplementary Figure S5b). In turn, we found that shRNA-mediated knockdown of CypA enhanced cell death in the presence of cisplatin for both HeLa and HCT116 cells (Figures 6a and b, right panels).

Because shRNA knockdown data do not provide clear evidence of how cis-trans prolyl isomerisation of p38MAPK is involved in regulating the sensitivity of tumour cells to cisplatin, we next tested the viability of E1A+Ras-transformed MEFs after increasing doses of cisplatin. We found that P224I p38MAPK-transformed cells showed an increased sensitivity to cisplatin determined by analysis of colony viability and a cell death (Figure $6 \mathrm{c}$ and Supplementary Figures S5a and c) similar to that observed for CypA- and p38MAPK-depleted tumour cells. In addition, as demonstrated for HeLa cells, transformed MEFs with substituted Pro224 could not grow at clonal density, which was reflected in a lower number of clones of non-treated cells (Figure 6c); the proliferation rate of individual cells was not affected (Supplementary Figure S5b).

Next, we turned to the analysis of the role of p38 Pro224 isomerisation in vivo by injecting transformed MEFs into immunodeficient nude mice. Once tumours appeared, mice were treated with cisplatin ( $7 \mathrm{mg} / \mathrm{kg}$ twice with a 4-day interval) 

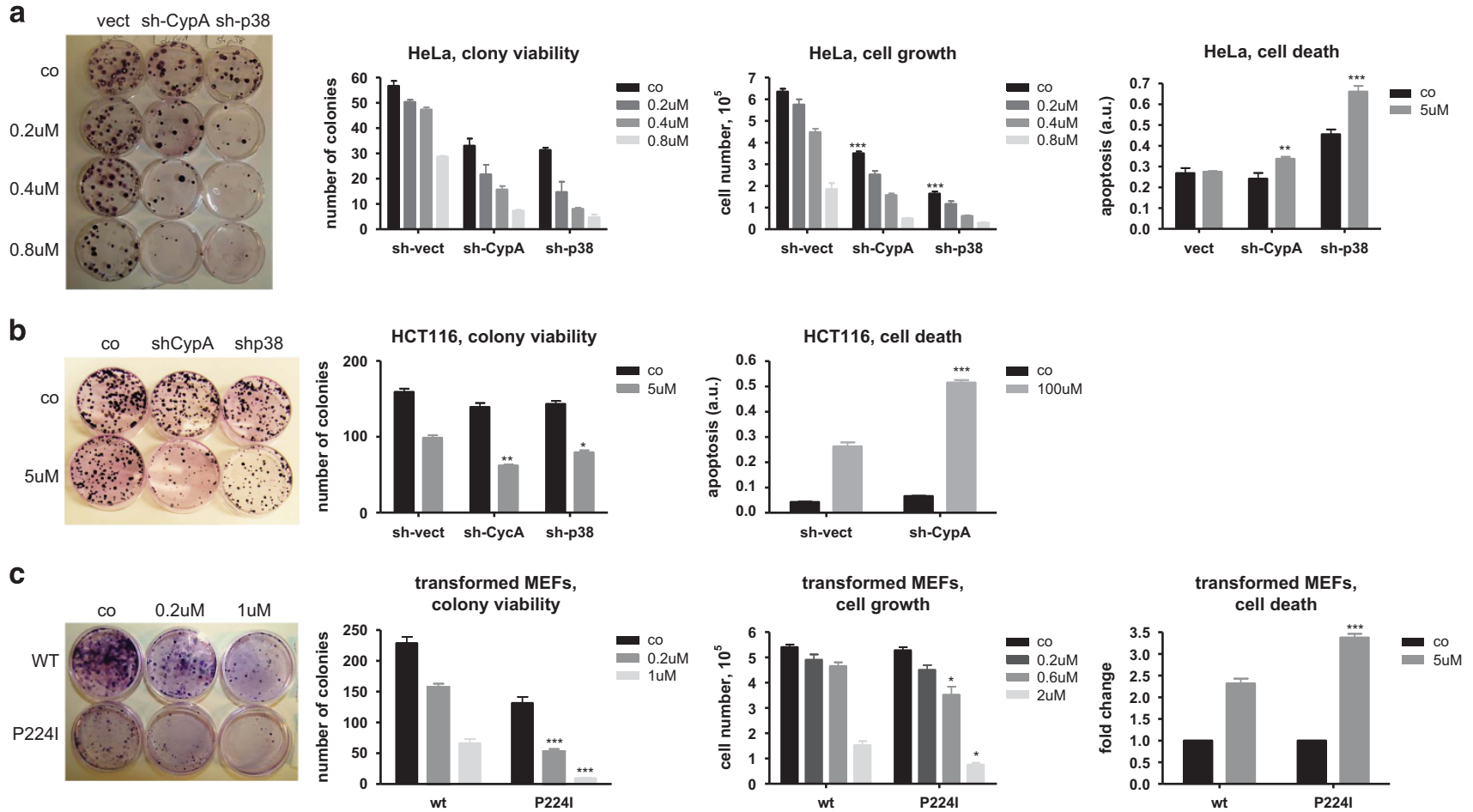

Figure 6 Knockdown of cyclophilin A or p38MAPK sensitises tumour cells to cisplatin. (a) HeLa cells were stably infected with a lentivirus containing an shRNA targeting human CypA, or p38MAPK or a backbone vector. After 1 week of puromycin selection cells were plated at clonal density $7 \times 10^{3}$ cells per $3 \mathrm{~cm}$ dish in triplicates and treated for $4 \mathrm{~h}$ with different concentrations of cisplatin. Cells were washed and left in growing media until visible colonies were formed (10-14 days). The numbers of colonies or cell numbers were counted and presented as an image and a graph. The numbers of colonies in the controls were used as $100 \%$ for each individual cell line, and number of colonies and cells viable after treatment was presented as \% relative to the control (shown in Supplementary Figure S5a). On the right, HeLa cells were treated with $5 \mu \mathrm{M}$ cisplatin for $6 \mathrm{~h}$ and the extent of apoptosis was measured with a Cell Death Detection ELISA kit (Roche). (b) HCT116 cells were stably infected with a lentivirus containing an shRNA for human CypA, or p38MAPK or a backbone vector. After 1 week of puromycin selection, cells were treated with $5 \mu \mathrm{M}$ cisplatin for $4 \mathrm{~h}$, then plated at clonal density $1 \times 10^{3}$ on $3 \mathrm{~cm}$ dishes in triplicates. Cells were left growing until visible colonies were formed (10-14 days). The numbers of colonies were counted, and the results are presented as an image and a graph. On the right, HCT116 cells were treated with $100 \mu \mathrm{M}$ cisplatin for $12 \mathrm{~h}$ and the extent of apoptosis was measured with a Cell Death Detection ELISA kit (Roche). (c) MEFs from wild type and P224l knock-in embryos were transformed with E1A and RasV12 oncogenes. Established cell lines were plated in triplicates at clonal density $7 \times 10^{3} \mathrm{cells}$ per $3 \mathrm{~cm}$ dish and after $24 \mathrm{~h}$ were treated with various concentrations of cisplatin for $4 \mathrm{~h}$, washed and left growing until colonies were visible to count (10-14 days). As P224l transformed MEFs are less viable when seeded at clonal density than wild-type MEFs, the number of visible colonies in a control was used as $100 \%$ for each cell line, and the number of colonies viable after treatment was present as \% relative to the control (shown in Supplementary Figure S5a). On the right, transformed MEFs were treated with $5 \mu \mathrm{M}$ cisplatin for $12 \mathrm{~h}$ and apoptosis was measured with a Cell Death Detection ELISA kit (Roche). Results of cell death for the second pair of E1a+Ras-transformed MEFs treated with $5 \mu \mathrm{M}$ cisplatin are presented in Supplementary Figure S5c. ${ }^{*} P<0.05 ;{ }^{* *} P<0.01 ;{ }^{* * *} P<0.001$

and killed when the size of tumours in untreated mice reached $2 \mathrm{~cm}$. While E1A+Ras-transformed P224I MEFs demonstrated a more aggressive tumour growth after injecting into nude mice, tumour size and weight was significantly reduced when compared with wt cells after cisplatin treatment (Figure 7a and Supplementary Figure S6a). We further found a significant increase in the number of cleaved caspase-3 (CC3)-positive apoptotic cells in P224I p38MAPK-transformed cells when compared with wt cells (Figure $7 \mathrm{~b}$ and Supplementary Figure S6b).

Cisplatin is one of the broadly employed drugs in cancer therapy and is currently used to treat lung cancer. Thus, finding ways to improve its efficiency is of paramount significance. Based on our data, we speculated that lung tumours that developed in P224I p38 homozygous mice could be more sensitive to cisplatin treatment compared with wt mice. To verify this, we next turned to a model of lung cancer based on somatic expression of a mutant K-ras (K-rasG12D/+). ${ }^{28} \mathrm{Wt}$ and $\mathrm{P} 224 \mathrm{I}$ knock-in littermates, both carrying the K-ras mutation, were established and used for further analysis. First, we found that the p38MAPK signalling pathway was significantly activated in tumour lesions based on the analysis of phosphorylation of p38 itself and a downstream target, Hsp27. This further suggested that p38MAPK could play a role in lung tumorigenesis (Figure 7c and Supplementary Figure S6c). Our analysis of tumour lungs from P224I mice further revealed that p38 and Hsp27 phosphorylation was significantly attenuated as shown by immunohistochemistry staining with subsequent quantification of the staining intensity (Figure 7c). Furthermore, we observed that the expression of known p38 target genes, Cxcl5, TNFa and MMP12, was reduced in micro-dissected tumour lesions from $\mathrm{P} 224 \mathrm{I}$ mice compared with wt mice (Figure 7d).

Next we analysed lung tumour development in wt and P224I p38MAPK mice. We found that the number of tumour lesions at 10 weeks was significantly reduced in P224l p38 knock-in mice (Figure 7e). This reduction further correlated with a significant reduction in overall tumour area in P224I p38MAPK 

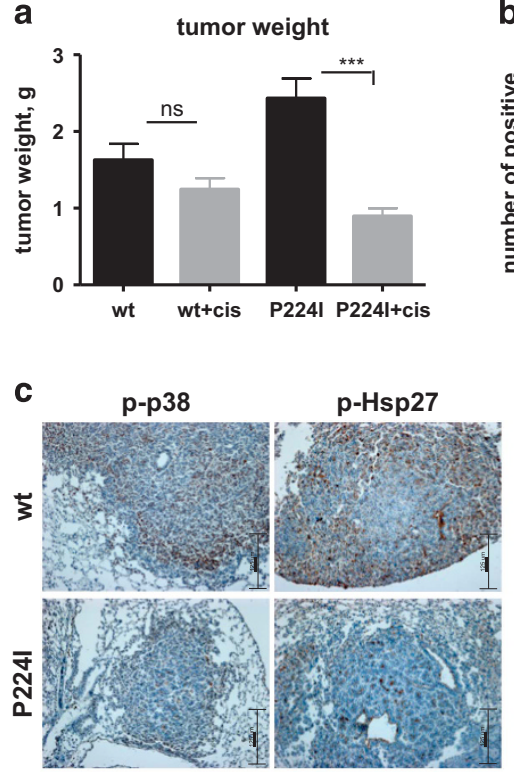

e

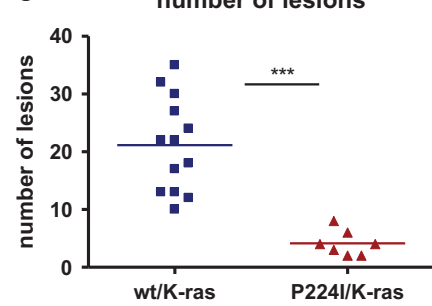

b

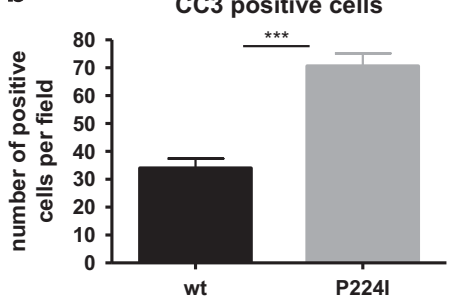

Cisplatin treatment

Staining intensity $(n=10)$

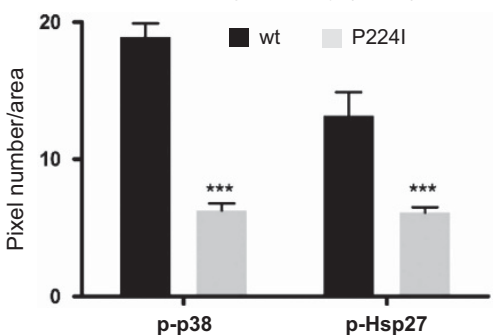

$\%$ of tumor area
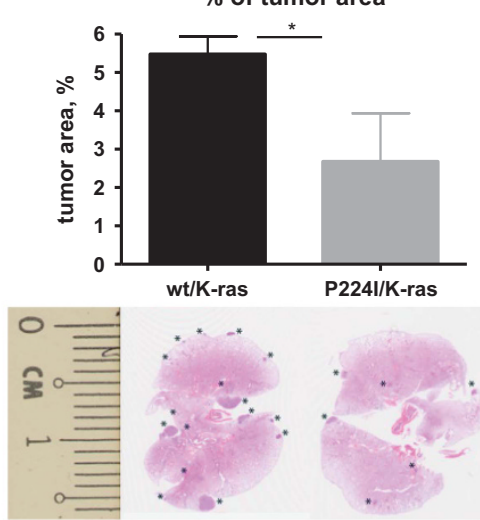

d

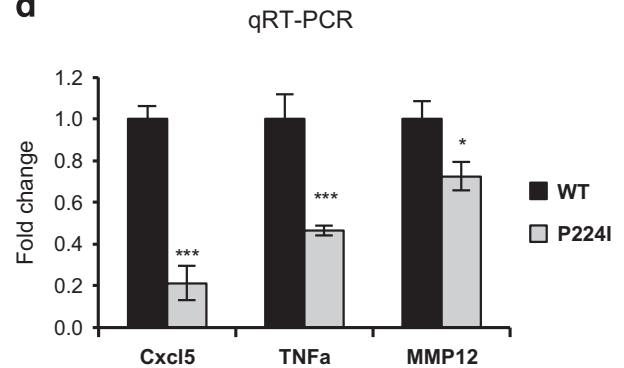

g

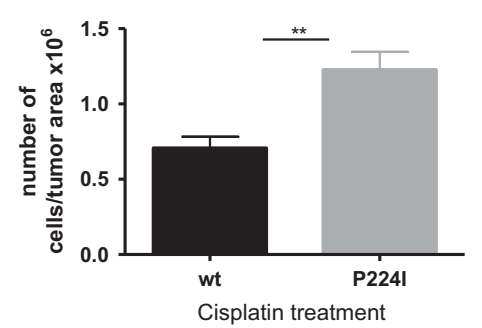

Figure 7 Inactivation of p38MAPK due to lack of Pro224 isomerisation leads to a higher sensitivity of tumour cells to cisplatin treatment. (a) Wild-type MEFs or P224I MEFs were transformed with E1A and RasV12 oncogenes, and established stable cell lines were xenografted into nude mice subcutaneously $\left(1 \times 10^{5}\right.$ cells per flank, left side for wildtype cells, right side for knock-in cells). Once the tumours reach $1 \mathrm{~cm}$ in diameter (10-14 days), one group of mice was left untreated (at least three mice per group), and the second group of mice was treated with cisplatin at a dose of $7 \mathrm{mg} / \mathrm{kg}$, two times with a 4-days interval. Mice were killed once the tumour size of control mice reached about $2 \mathrm{~cm}$ in diameter. Solid tumours were excised, weighted and photographed. The graph represents an average weight of all tumours per genotype/treatment. (b) Histological sections of subcutaneously xenografted cells collected after cisplatin treatment as in Figure 7a. Paraffin sections were stained with anti-cleaved caspase-3 antibodies (CC3), the number of cells per field ( $\times 20$ objective) was counted and presented as a graph. One representative image of CC3 staining is presented in Supplementary Figure S6b. (c) Wild type and homozygous P224I knock-in mice were crossed on a K-ras background to develop lung tumours and killed at an age of 10 weeks. Histological sections were stained with phospho-specific antibodies against p38 and Hsp27, and representative images are shown. Staining intensity of images taken at $\times 60$ objective $(n=10)$ was quantified using ImageJ program and presented in the graph. A representative image is shown in Supplementary Figure S6c. (d) Visible lung tumour lesions were micro-dissected from three pairs of wild type and P224I mice, and processed for mRNA expression analysis of p38 targets by qRT-PCR. (e) Wild type and P224I knock-in mice were crossed on a K-ras background to develop lung tumours and killed at the age of 10 weeks The numbers of lesions were counted and presented. (f) The relative tumour area was calculated after hematoxylin/eosin staining and the percentage relative to total lung area is presented. A representative image of the lung section is shown; note the dark hematoxylin/eosinpositive nodules (indicated with arrows) on the surface of the lungs representing tumour lesions. (g) Wild type and homozygous P224l knock-in mice were crossed on a K-ras background to develop lung tumours. At the age of 10 weeks, mice were injected with cisplatin. Apoptosis was analysed with an anti-cleaved caspase-3 antibody; the number of positive cells was counted and presented as a ratio per scored tumour area. One representative image is shown in Supplementary Figure S6d. NS stands for nonsignificant, ${ }^{*} P<0.05,{ }^{* *} P<0.01,{ }^{* * *} P<0.001$

knock-in mice (Figure 7f). Next, mice at age 10 weeks were treated intraperitoneally with a single dose of cisplatin $(7 \mathrm{mg} / \mathrm{kg})$. The maximum apoptotic response in K-ras lung tumours is reported to occur at $24 \mathrm{~h}$ after cisplatin treatment, ${ }^{29}$ and we analysed the apoptotic response at this time point by measuring the number of CC3-positive cells (Figure $7 \mathrm{~g}$ and Supplementary Figure S6d). The number of CC3-positive cells per tumour area was significantly higher in tumours of P224I p38MAPK mice, suggesting that the lack of Pro224 isomerisation of p38MAPK sensitises lung tumours to cisplatin treatment. Thus, our data argue that p38MAPK isomerisation at Pro224 could be critical in regulating K-ras-driven lung tumorigenesis in mice and controlling sensitivity in response to cisplatin. 


\section{Discussion}

The p38MAPK signalling pathway plays an important role in integrating numerous extracellular signals to generate an appropriate response to different stimuli. Regardless of the type of stress that triggers p38MAPK activation, it will be executed through phosphorylation of the activation sites Thr180 and Tyr182. Here we report that this phosphorylation-dependent mechanism of p38MAPK activation itself is actively regulated by cis-trans peptidyl-prolyl isomerisation of Pro224. This mechanism is mediated by direct association with cyclophilins, and in turn, proline isomerisation changes the structure of p38MAPK, making it more accessible for upstream kinases to phosphorylate Thr180/Tyr182.

Proline isomerisation has been reported for another stress kinase, JNK1; however, it is modulated in that case by interaction with phosphorylation-dependent isomerase Pin1 at the phospho-Thr-Pro motif. ${ }^{22}$ Pin1 is the only proline isomerase that can catalyse the isomerisation of the $\mathrm{pS} / \mathrm{T}-\mathrm{P}$ bond, and it regulates numerous serine-threonine kinases and transcription factors. ${ }^{30,31}$

Most cyclophilin targets have been predicted based on the correlation between cyclophilin levels and the activity of the protein of interest. For example, the stability, localisation and activity of the p65 subunit of NF- $k B$ was recently shown to be regulated by association with $\mathrm{CypA}$ because its downregulation impaired production of NF- $\kappa \mathrm{B}$-induced cytokines while reducing the proliferation of glioblastoma cells. ${ }^{32,33}$ Similar to CypA, genetic ablation of CypB reduces glioma cell survival and proliferation, as shown both in vitro and in vivo. ${ }^{34,35} \mathrm{We}$ found that multiple cyclophilins - СурА, СурВ and $\mathrm{CypH} \mathrm{-} \mathrm{directly} \mathrm{interact} \mathrm{with} \mathrm{a} \mathrm{newly} \mathrm{identified} \mathrm{target,}$ p38MAPK, facilitating isomerisation of Pro224, which in turn is required to regulate phosphorylation of kinase regulatory Thr-Gly-Tyr motif. As a result, cyclophilin-mediated regulation of p38MAPK could be an additional way of controlling cell survival; as shown in Figure 6, both HeLa cells with downregulated CypA and transformed MEFs expressing an isomerisation-deficient p38MAPK are less viable when growing at clonal density.

Different cyclophilin isoforms are located in the cytoplasm, similar to p38MAPK. CypA is the most well-characterised cyclophilin and has been implicated in many diseases. Upregulation of CypA or СypB has been found in primary human cancers. ${ }^{34,36-40}$ In some cases, this upregulation has been associated with enhanced metastasis, radioresistance and poor clinical prognosis. ${ }^{41,42}$ Although the direct correlation between expression of cyclophilins and phosphorylation of p38MAPK has not been established, increased levels of phosphorylated p38MAPK have been described in various cancers. $^{8,9,12-14,35,43}$ In this study, we found that cyclophilinmediated isomerisation could be a critical step in the activation of p38MAPK, which could explain the correlative evidence in the literature concerning the overexpression of cyclophilins and an increase in p38MAPK phosphorylation. This in turn could suggest that different cyclophilins and in particular CypA can function as a molecular switch to modulate p38MAPK signalling to adjust to environmental changes, thus modulating cancer cell survival.
Previous studies have speculated that overexpression of cyclophilins in various cancers could play a cytoprotective role. Several reports have suggested inactivating CypA in combination with the cytotoxic anti-cancer drugs cisplatin or paclitaxel to improve the chemosensitivity of cancer cells. $^{26,40,44,45}$ However, the few clinical studies that have used a combination of platinum-based chemotherapy with cyclosporine A have shown low cooperative anti-cancer activity. ${ }^{46}$ Despite being widely used as an inhibitor of cyclophilins, cyclosporine A does not have a broad inhibitory activity towards different isoforms. Thus, there is a need for further development of cyclophilin inhibitors with broader and stronger inhibitory activity than cyclosporine A.

Increasing in vivo and in vitro evidence suggests that downregulation of p38 kinase potentiates the effect of chemotherapy. ${ }^{16,17,47,48}$ Here we show that downregulation of p38MAPK activity by attenuation of its isomerisation either by mutation of Pro224 or by knock down of CypA leads to higher sensitivity to cisplatin. This combinatory effect of cisplatin with aberrantly activated p38MAPK was demonstrated in several cell lines (Figure 6), as well as with a mouse model of lung tumorigenesis (Figures $7 \mathrm{e}-\mathrm{g}$ ). These findings further support the idea that the use of cyclophilin inhibitors could sensitise platinum-based anti-cancer drugs.

Several studies using conditional knockout mice with deletion of p38a or MK2 in lung epithelium have demonstrated that downregulation of the p38 pathway enhances lung tumorigenesis induced by oncogenic K-ras. ${ }^{8,49}$ In contrast, in this study, we show a significant reduction in K-ras-induced lung tumours in P224I p38MAPK mice. In addition, these mice appeared to be more sensitive to cisplatin treatment. Our results clearly show that blocking cis-trans peptidyl-prolyl isomerisation of p38MAPK is sufficient to reduce K-ras-driven lung tumorigenesis. This finding in turn supports the hypothesis that targeting cyclophilin-mediated isomerisation of p38MAPK could be an attractive pathway for drug discovery. We speculate that efficient cyclophilin inhibitors can serve in anti-lung cancer therapy as mono drugs or in combination with cisplatin-based therapies.

\section{Materials and Methods}

Animals, cell culture conditions and treatments. All animal protocols used in this study were approved by the Institute of Molecular and Cell Biology Animal Safety and Use Committee. To generate P224l knock-in mice the targeting vector described in Wong et al..$^{50}$ was used that contained the equivalent of $4.5 \mathrm{~kb}$ of mouse DNA with an exon containing the Pro224 sites of p38MAPK. This site was mutated to isoleucine by site-directed mutagenesis (SDM primers: $5^{\prime}$-GCTGGTT AATATGGTCTGTACCAATAAACAACGTTCTTCCGGTC-3'; 5'-GACCGGAAGAACG TTGTTTATTGGTACAGACCATATTAACCAGC-3'). Targeted ES clones were generated, positive clones were screened by PCR and Southern blot analysis, karyotyped and one of the clones was used for blastocyst injection to generate mice in the C57B//6 background. P224I+ - mice were interbred to generate littermates with the following genotypes: P224I+/+ (wt type) and P224I - / - MEFs were purified from 12.5 days embryos. Mice with somatic activation of $\mathrm{K}$-ras were described in Johnson et al. (2001) 28 and were purchased from the Jackson Laboratory (Bar Harbor, ME, USA).

MEF, HeLa and HCT116 cells were maintained in DMEM medium supplemented with $10 \%$ fetal bovine serum (Hyclone, South Logan, UT, USA), $100 \mathrm{U} / \mathrm{ml}$ of penicillin and $0.1 \mathrm{mg} / \mathrm{ml}$ of streptomycin (Gibco, Grand Island, NY, USA). For SILAC, HeLa cells were grown in SILAC DMEM and 10\% dialyzed FBS supplemented with Larginine and L-lysine for the light culture or with L-arginine (U-13C6) and L-lysine (U-13C6) for the heavy culture (Thermo Scientific, Waltham, MA, USA). The cells 
were used after six doublings in SILAC media to allow for full metabolic incorporation. Cisplatin $(100 \mu \mathrm{M})$, TMN355 $(1 \mu \mathrm{M}), 0.5 \mathrm{M}$ sorbitol or $20 \mathrm{~J} / \mathrm{m}^{2}$ of UV radiation were used for the treatments and cells were harvested when appropriate.

Plasmids. shRNA lentiviral constructs in the pLKO.1 vector targeting human p38MAPK and cyclophilin A were purchased from Dharmacon (Lafayette, Columbia USA), and the most potent clones were used for further studies. Flag-tagged cyclophilin A, cyclophilin B, cyclophilin $\mathrm{H}$ and CWC27 were purchased from Origene (Rockville, MD, USA) (in pCMV-entry vector). Full-length human p38MAPK was cloned into the pGEX-4T vector, into pEGFP-C1 or pcDNA3.1/His, with the subsequent mutation of Pro224 to lle generated by PCR-based site-directed mutagenesis. Plasmids were transfected into cells using Lipofectamine 2000 (Invitrogen, Waltham, MA, USA).

For the transfection of HeLa cells with the increasing concentrations of cyclophilincoding plasmids, cells were seeded in $60 \mathrm{~mm}$ dishes; the plasmid amount used was: $1 \mu \mathrm{g}$ of GFP-tagged p38MAPK plasmid, $0.1 \mu \mathrm{g}$ of MKK6-EE plasmid and $0.5,1$ or $3 \mu \mathrm{g}$ of plasmid coding cyclophilins. Cells were used $24 \mathrm{~h}$ after transfection.

Cell lysis, immunoprecipitation and immunoblotting. Cells were lysed in buffer (10 mM Tris-HCl, pH 7.5, 2 mM EDTA, $137 \mathrm{mM} \mathrm{NaCl}, 10 \%$ glycerol and $1 \%$ Triton $\mathrm{X}-100)$ containing protease and phosphatase inhibitors cocktail (Roche, Basel, Switzerland). For GFP-trap immunoprecipitation, cells were lysed in RIPA buffer (10 mM Tris-HCl, pH 7.5, $150 \mathrm{mM} \mathrm{NaCl}, 2 \mathrm{mM}$ EDTA, 1\% Triton, 0.1\% SDS) and the lysate was diluted with wash buffer (10 mM Tris-HCl, pH 7.5, $150 \mathrm{mM}$ $\mathrm{NaCl}, 2 \mathrm{mM}$ EDTA) to bring the Triton to $0.2 \%$ and incubated with GFP-trap beads (Chromotek, Planegg, Germany) for $4 \mathrm{~h}$ at $4{ }^{\circ} \mathrm{C}$. The immunoprecipitates were washed three times with wash buffer and boiled in protein sample buffer, analysed by SDS-PAGE followed by western blotting. For immunoprecipitation of flag-tagged cyclophilins, anti-flag M2 agarose (Sigma, St. Louis, MO, USA) was used, cells were lysed in NP-40 lysis buffer (0.5\% NP-40, $10 \mathrm{mM}$ Tris- $\mathrm{HCl}, \mathrm{pH}=7.5,150 \mathrm{mM} \mathrm{NaCl}$, $2 \mathrm{mM}$ EDTA). TALON beads were used for immunoprecipitation of his-tagged $\mathrm{p} 38$. For the detection of p38MAPK interacting proteins by MS, $10 \mathrm{mg}$ of total cell lysate proteins were used. The lysates were incubated with GFP-trap beads, the beads were washed, combined and washed three more times before boiling in sample buffer. The samples were separated on SDS/PAGE gels and MS was performed. Each experiment was carried out at least three times.

For quantification of bands intensity on western blots, a Gel-Pro analazer program was used. A ratio of specific bands to either total p38 or tubulin was generated and presented at each panel, and non-treated control was served as 1 for all western blots.

Antibodies used were the following: p38 $\alpha$ (C-20; Santa Cruz, Dallas, TX, USA), FLAG (4C5; Origene), Tyr182 phospho-p38MAPK (gift from A Fornace), TY-phosphop38MAPK (\#9211; Cell Signalling, Danvers, MA, USA), phosphor-Thr334-MK2 (27B7; Cell Signalling), cyclophilin A (H-24; Santa Cruz), phosphor-S86-HSP27 (\#17938; Abcam, Cambridge, UK) and cleaved caspase-3 (\#559565; BD, Franklin Lakes, NJ, USA).

In vitro kinase assay. For in vitro kinase assays, purified recombinant human p38MAPK protein (either manually purified or purchased from SignalChem, Richmond, BC, Canada) was preincubated with purified cyclophilin A (Peprotech, Rocky Hill, NJ, USA) in isomerisation buffer ( $43 \mathrm{mM}$ Hepes, $86 \mathrm{mM} \mathrm{NaCl}, 10 \mathrm{mM}$ $\mathrm{LiCl})$ for $15 \mathrm{~min}$ on ice and then incubated with purified active MKK6 kinase (Biaffin, Kassel, Germany) in kinase buffer (20 mM Tris, pH 7.5, $10 \mathrm{mM} \mathrm{MgCl}$ ) supplemented with $50 \mu \mathrm{M}$ ATP at $30^{\circ} \mathrm{C}$ for $15 \mathrm{~min}$. The reaction was stopped by the addition of 0.5 volume of $2 \times$ protein sample buffer. The proteins were resolved by SDS-PAGE. The phosphorylation of p38MAPK was visualised by western blotting using phospho-specific antibodies.

BrDU incorporation. DNA replication was measured by adding $10 \mu \mathrm{M} \mathrm{BrDU}$ to the cell culture medium 45 min before the cells were harvested and fixed in $70 \%$ EtOH. BrDU-positive cells were detected with FITC-conjugated anti-BrDU antibodies (BD kit), co-stained with propidium iodate and analysed by flow cytometry.

Immunohistochemistry. Tissue samples were fixed in 4\% PFA overnight before alcohol dehydration, clearing with xylene and wax embedding. Samples were cut into $5 \mu \mathrm{m}$ sections. Paraffin-embedded sections were deparaffinised in xylene and rehydrated in ethanol with increasing concentrations of water. Antigen retrieval was performed at $90-95{ }^{\circ} \mathrm{C}$ in the presence of $1 \mathrm{mM}$ EDTA pH 9.0 for $35 \mathrm{~min}$. Samples were permeabilised with $0.3 \%$ Triton X-100 in PBS. Rabbit antibodies against mouse cleaved caspases $3(\mathrm{BD})$, phospho-p38 (Cell Singaling) and phospho-Hsp27 (Cell Signalling) were used for analysis. Intensity of p-p38 and p-HSP27 staining was quantified using ImageJ program with 10 images per analysis ( $\times 60$ objective).

Assay for peptidyl prolyl isomerisation. One microliter of cyclophilins (3-7 nM) was dissolved in the assay buffer $(86.5 \mu \mathrm{l}$, final concentration $43 \mathrm{mM}$ Hepes, $86 \mathrm{mM} \mathrm{NaCl}, \mathrm{pH}$ 8.0). The pNA-modified peptide substrates (synthesised by Shanghai Hanhong Chemical Co., Ltd, China) were dissolved in TFE that contained $\mathrm{LiCl}(400 \mathrm{mM})$ and added into buffer with cyclophilins. Final concentration of $\mathrm{LiCl}$ in the assay was $10 \mathrm{mM}$; TFE was at the concentration $2.5 \%$ (v/v), mixed and preequilibrated on ice for $30 \mathrm{~min}$. Immediately before the assay was started, $10 \mu \mathrm{l}$ of chymotrypsin solution $(60 \mathrm{mg} / \mathrm{ml}$ in $0.001 \mathrm{M} \mathrm{HCl}$, final concentration $6 \mathrm{mg} / \mathrm{ml})$ was added into the cuvette and the absorbance of $p$-nitroaniline was followed at $390 \mathrm{~nm}$ until the reaction was completed $(5 \mathrm{~min})$.

Colony-forming assay and apoptosis analysis. For analysis of the response of the cells to cisplatin, different cell lines were seeded at clonal density onto $35 \mathrm{~mm}$ dishes in triplicates $\left(7 \times 10^{3}\right.$ cells per $35 \mathrm{~mm}$ dish for HeLa and transformed MEFs; $1 \times 10^{3}$ cells for HCT cells). The next day cisplatin in increasing concentrations was added, $4 \mathrm{~h}$ later cells were washed and left growing for 10-14 days until colonies were visible. Cells were washed and stained before counting with $1 \%$ crystal violet solution in fixative buffer.

For apoptosis assays, cells were seeded onto 96-well plates, $24 \mathrm{~h}$ later were treated with cisplatin at the concentration of $5 \mu \mathrm{M}$ for HeLa cells, $100 \mu \mathrm{M}-$ for HCT116 cells for the indicated times, washed and analysed using the Cell Death Detection kit ELISA PLUS (Roche Diagnostics) following the manufacturer's instructions.

Tumour cells xenografts. Wt MEFs or P224l MEFs were transformed with E1A and RasV12 oncogenes; established stable cell lines were xenografted into nude mice subcutaneously as $1 \times 10^{5}$ cells per flank with at least three mice per group. Ten to 14 days later, once tumours reached $1 \mathrm{~cm}$ in diameter, one group of mice was left untreated, another group of mice was treated with cisplatin at a dose of $7 \mathrm{mg} / \mathrm{kg}$, two times with a 4-days interval. Mice were killed once tumour size of the control mice reached about $2 \mathrm{~cm}$ in diameter. Solid tumours were excised, weighted and imaged. The two longest perpendicular axes in the $x y y$ plane of each xenograft tumour were measured with a caliper, and tumour volume was calculated as $x y^{2} / 2$.

RNA expression/quantitative real-time PCR. Cells or excised lung tumours were harvested in Trizol (Invitrogen) and processed for total RNA purification. Trizol-based purified total RNA was used for cDNA reverse transcription using Maxima $\mathrm{H}$ Minus First Strand cDNA synthesis kit (Thermofischer, Waltham, MA, USA) with oligo-dT primers. Quantitative PCR reactions were performed using KAPA SYBR Fast Universal qPCR kit reagents with the Applied Biosystems 7300 Real-time PCR System and specific primers.

Statistical analysis. Values are means \pm S.E.M. Comparison of mean values between groups was evaluated by two-tailed Student's $t$-test using the Prizm program. $P$-values less than 0.05 were considered significant. Any $P$-value less than 0.05 was designated with one $\left(^{*}\right)$ asterisk; less than $0.01-$ with two $\left(^{* *}\right)$ asterisks, less than $0.001-$ with three $\left.{ }^{* * \star}\right)$ asterisks.

\section{Conflict of Interest}

The authors declare no conflict of interest.

Acknowledgements. The research of DVB was supported by the Foundation ARC (France) and for AB by A*STAR's JCO project grant 14302FG090 (Singapore). We are grateful to Dr. Elise Courtois, Jun Siong Low, Nancy Zhao Qi and Matthias Schmitt for the assistance.

1. Freshney NW, Rawlinson L, Guesdon F, Jones E, Cowley S, Hsuan J et al. Interleukin-1 activates a novel protein kinase cascade that results in the phosphorylation of Hsp27. Cell 1994; 78: 1039-1049.

2. Lee JC, Laydon JT, McDonnell PC, Gallagher TF, Kumar S, Green D et al. A protein kinase involved in the regulation of inflammatory cytokine biosynthesis. Nature 1994; 372: 739-746. 
3. Bulavin DV, Higashimoto Y, Popoff IJ, Gaarde WA, Basrur V, Potapova O et al. Initiation of a G2/M checkpoint after ultraviolet radiation requires p38 kinase. Nature 2001; 411: 102-107.

4. Han J, Lee JD, Bibbs L, Ulevitch RJ. A MAP kinase targeted by endotoxin and hyperosmolarity in mammalian cells. Science 1994; 265: 808-811.

5. Reinhardt HC, Aslanian AS, Lees JA, Yaffe MB. p53-deficient cells rely on ATM- and ATRmediated checkpoint signaling through the p38MAPK/MK2 pathway for survival after DNA damage. Cancer Cell 2007; 11: 175-189.

6. Bulavin DV, Demidov ON, Saito S, Kauraniemi P, Phillips C, Amundson SA et al. Amplification of PPM1D in human tumors abrogates p53 tumor-suppressor activity. Nat Genet 2002; 31: 210-215

7. Hui L, Bakiri L, Mairhorfer A, Schweifer N, Haslinger C, Kenner L et al. p38alpha suppresses normal and cancer cell proliferation by antagonizing the JNK-c-Jun pathway. Nat Genet 2007; 39: 741-749.

8. Ventura JJ, Tenbaum S, Perdiguero E, Huth M, Guerra C, Barbacid M et al. p38alpha MAP kinase is essential in lung stem and progenitor cell proliferation and differentiation. Nat Genet 2007; 39: 750-758.

9. Esteva FJ, Sahin AA, Smith TL, Yang Y, Pusztai L, Nahta R et al. Prognostic significance of phosphorylated P38 mitogen-activated protein kinase and HER-2 expression in lymph nodepositive breast carcinoma. Cancer 2004; 100: 499-506.

10. Wang SN, Lee KT, Tsai CJ, Chen YJ, Yeh YT. Phosphorylated p38 and JNK MAPK proteins in hepatocellular carcinoma. Eur J Clin Invest 2012; 42: 1295-1301.

11. Elenitoba-Johnson KS, Jenson SD, Abbott RT, Palais RA, Bohling SD, Lin Z et al. Involvement of multiple signaling pathways in follicular lymphoma transformation: p38mitogen-activated protein kinase as a target for therapy. Proc Natl Acad Sci USA 2003; 100 : 7259-7264.

12. Pomerance M, Quillard J, Chantoux F, Young J, Blondeau JP. High-level expression, activation, and subcellular localization of p38-MAP kinase in thyroid neoplasms. J Pathol 2006; 209: 298-306

13. Greenberg AK, Basu S, Hu J, Yie TA, Tchou-Wong KM, Rom WN et al. Selective p38 activation in human non-small cell lung cancer. Am J Respir Cell Mol Biol 2002; 26: 558-564.

14. Demuth T, Reavie LB, Rennert JL, Nakada M, Nakada S, Hoelzinger DB et al. MAP-ing glioma invasion: mitogen-activated protein kinase kinase 3 and p38 drive glioma invasion and progression and predict patient survival. Mol Cancer Ther 2007; 6: 1212-1222.

15. Tsai MS, Weng SH, Chen HJ, Chiu YF, Huang YC, Tseng SC et al. Inhibition of p38 MAPKdependent excision repair cross-complementing 1 expression decreases the DNA repair capacity to sensitize lung cancer cells to etoposide. Mol Cancer Ther 2012; 11: 561-571.

16. Germani A, Matrone A, Grossi V, Peserico A, Sanese P, Liuzzi M et al. Targeted therapy against chemoresistant colorectal cancers: inhibition of p38alpha modulates the effect of cisplatin in vitro and in vivo through the tumor suppressor FoxO3A. Cancer Lett 2014; 344: 110-118.

17. Pereira L, Igea A, Canovas B, Dolado I, Nebreda AR. Inhibition of p38 MAPK sensitizes tumour cells to cisplatin-induced apoptosis mediated by reactive oxygen species and JNK. EMBO Mol Med 2013; 5: 1759-1774.

18. Wilson KP, Fitzgibbon MJ, Caron PR, Griffith JP, Chen W, McCaffrey PG et al. Crystal structure of p38 mitogen-activated protein kinase. J Biol Chem 1996; 271: 27696-27700.

19. Lu KP, Finn G, Lee TH, Nicholson LK. Prolyl cis-trans isomerization as a molecular timer. Nat Chem Biol 2007; 3: 619-629.

20. Theuerkorn M, Fischer G, Schiene-Fischer C. Prolyl cis/trans isomerase signalling pathways in cancer. Curr Opin Pharmacol 2011; 11: 281-287.

21. Nelson CJ, Santos-Rosa H, Kouzarides T. Proline isomerization of histone H3 regulates lysine methylation and gene expression. Cell 2006; 126: 905-916.

22. Park JE, Lee JA, Park SG, Lee DH, Kim SJ, Kim HJ et al. A critical step for JNK activation: isomerization by the prolyl isomerase Pin1. Cell Death Differ 2012; 19: 153-161.

23. Herberich B, Cao GQ, Chakrabarti PP, Falsey JR, Pettus L, Rzasa RM et al. Discovery of highly selective and potent p38 inhibitors based on a phthalazine scaffold. J Med Chem 2008; 51: 6271-6279.

24. Kofron JL, Kuzmic P, Kishore V, Colon-Bonilla E, Rich DH. Determination of kinetic constants for peptidyl prolyl cis-trans isomerases by an improved spectrophotometric assay. Biochemistry 1991; 30: 6127-6134

25. Lee J, Kim SS. Current implications of cyclophilins in human cancers. J Exp Clin Cancer Res 2010; $29: 97$.

26. Choi KJ, Piao YJ, Lim MJ, Kim JH, Ha J, Choe W et al. Overexpressed cyclophilin A in cancer cells renders resistance to hypoxia- and cisplatin-induced cell death. Cancer Res 2007; 67: 3654-3662.

27. Galan-Moya EM, de la Cruz-Morcillo MA, Llanos Valero M, Callejas-Valera JL, Melgar-Rojas P, Hernadez Losa J et al. Balance between MKK6 and MKK3 mediates p38 MAPK associated resistance to cisplatin in NSCLC. PLoS One 2011; 6: e28406.
28. Johnson L, Mercer K, Greenbaum D, Bronson RT, Crowley D, Tuveson DA et al. Somatic activation of the K-ras oncogene causes early onset lung cancer in mice. Nature 2001; 410 : 1111-1116.

29. Oliver TG, Mercer KL, Sayles LC, Burke JR, Mendus D, Lovejoy KS et al. Chronic cisplatin treatment promotes enhanced damage repair and tumor progression in a mouse model of lung cancer. Genes Dev 2010; 24: 837-852.

30. Yaffe MB, Schutkowski M, Shen M, Zhou XZ, Stukenberg PT, Rahfeld JU et al. Sequencespecific and phosphorylation-dependent proline isomerization: a potential mitotic regulatory mechanism. Science 1997; 278: 1957-1960.

31. Litchfield DW, Shilton BH, Brandl CJ, Gyenis L. Pin1: intimate involvement with the regulatory protein kinase networks in the global phosphorylation landscape. Biochim Biophys Acta 2015; 1850: 2077-2086.

32. Sun S, Guo M, Zhang JB, Ha A, Yokoyama KK, Chiu RH et al. (CypA) interacts with NF. kappaB subunit, p65/RelA, and contributes to NF-kappaB activation signaling. PLoS One 2014; 9: e96211.

33. Sun $\mathrm{S}$, Wang $\mathrm{Q}$, Giang $A$, Cheng $\mathrm{C}$, Soo $\mathrm{C}$, Wang $\mathrm{CY}$ et al. Knockdown of CypA inhibits interleukin-8 (IL-8) and IL-8-mediated proliferation and tumor growth of glioblastoma cells through down-regulated NF-kappaB. J Neurooncol 2011; 101: 1-14.

34. Choi JW, Schroeder MA, Sarkaria JN, Bram RJ. Cyclophilin B supports Myc and mutant p53-dependent survival of glioblastoma multiforme cells. Cancer Res 2014; 74: 484-496.

35. Bauer K, Kretzschmar AK, Cvijic H, Blumert C, Loffler D, Brocke-Heidrich K et al. Cyclophilins contribute to Stat3 signaling and survival of multiple myeloma cells. Oncogene 2009; 28: 2784-2795

36. Lim SO, Park SJ, Kim W, Park SG, Kim HJ, Kim YI et al. Proteome analysis of hepatocellular carcinoma. Biochem Biophys Res Commun 2002; 291: 1031-1037.

37. Campa MJ, Wang MZ, Howard B, Fitzgerald MC, Patz EF Jr. Protein expression profiling identifies macrophage migration inhibitory factor and cyclophilin a as potential molecular targets in non-small cell lung cancer. Cancer Res 2003; 63: 1652-1656.

38. Li M, Zhai Q, Bharadwaj U, Wang H, Li F, Fisher WE et al. Cyclophilin A is overexpressed in human pancreatic cancer cells and stimulates cell proliferation through CD147. Cancer 2006; 106: 2284-2294.

39. Fang F, Flegler AJ, Du P, Lin S, Clevenger CV. Expression of cyclophilin B is associated with malignant progression and regulation of genes implicated in the pathogenesis of breast cancer. Am J Pathol 2009; 174: 297-308.

40. Han X, Yoon SH, Ding Y, Choi TG, Choi WJ, Kim YH et al. Cyclosporin A and sanglifehrin A enhance chemotherapeutic effect of cisplatin in C6 glioma cells. Oncol Rep 2010; 23 : 1053-1062.

41. Li Z, Zhao X, Bai S, Wang Z, Chen L, Wei Y et al. Proteomics identification of cyclophilin a as a potential prognostic factor and therapeutic target in endometrial carcinoma. Mol Cell Proteomics 2008; 7: 1810-1823.

42. Al-Ghoul M, Bruck TB, Lauer-Fields JL, Asirvatham VS, Zapata C, Kerr RG et al. Comparative proteomic analysis of matched primary and metastatic melanoma cell lines. J Proteome Res 2008; 7: 4107-4118.

43. Wu X, Zhang W, Font-Burgada J, Palmer T, Hamil AS, Biswas SK et al. Ubiquitin-conjugating enzyme Ubc13 controls breast cancer metastasis through a TAK1-p38 MAP kinase cascade. Proc Natl Acad Sci USA 2014; 111: 13870-13875.

44. Li Z, Min W, Gou J. Knockdown of cyclophilin A reverses paclitaxel resistance in human endometrial cancer cells via suppression of MAPK kinase pathways. Cancer Chemother Pharmacol 2013; 72: 1001-1011.

45. Nakahara C, Nakamura K, Yamanaka N, Baba E, Wada M, Matsunaga H et al. Cyclosporin-A enhances docetaxel-induced apoptosis through inhibition of nuclear factor-kappaB activation in human gastric carcinoma cells. Clin Cancer Res 2003; 9: 5409-5416.

46. Hamilton G. Cyclophilin A as a target of Cisplatin chemosensitizers. Curr Cancer Drug Targets 2014; 14: 46-58.

47. Paillas S, Boissiere F, Bibeau F, Denouel A, Mollevi C, Causse A et al. Targeting the p38 MAPK pathway inhibits irinotecan resistance in colon adenocarcinoma. Cancer Res 2011; 71: 1041-1049.

48. Rudalska R, Dauch D, Longerich T, McJunkin K, Wuestefeld T, Kang TW et al. In vivo RNAi screening identifies a mechanism of sorafenib resistance in liver cancer. Nat Med 2014; 20: 1138-1146.

49. Morandell S, Reinhardt HC, Cannell IG, Kim JS, Ruf DM, Mitra T et al. A reversible genetargeting strategy identifies synthetic lethal interactions between MK2 and p53 in the DNA damage response in vivo. Cell Rep 2013; 5: 868-877.

50. Wong ES, Le Guezennec X, Demidov ON, Marshall NT, Wang ST, Krishnamurthy J et al. p38MAPK controls expression of multiple cell cycle inhibitors and islet proliferation with advancing age. Dev Cell 2009; 17: 142-149. 